Induced estrus behaviour in the spaved rat. Arta Phrsiologica Scandinavica, 1964. Suppl. 241, 1-32

leversin $\mathrm{B}$. antidepressant drugs on estrus behaviour in ovariectomised rats activated by progesterone. reserpine. or tetrabenazine in combination with estrogen. Acta Physiologica Scandinavica. $1966,67,411-422$

Rech R H. \& Noore, K. E. An introduction to psyourmo York: Raven Press, 1971

Salis, P. J. \& Dewsburv. D. A. p-Chlorophenvlalanine facilitates alis, P. J.. \& Dewsbury. D. A. p-Chlorophentalanine facilitates
copulatory behaviour in male rats. Nature. 1971, 232. 400-401.
Simpson. G. M.. Blair, J. H.. \& Amuso. D. Effects of anti-depressants on genito-urinary function. Diseases of the Vervous System, 1965, 26, 787-789.

winer $\mathrm{B}$ Statistical principles in experimental design. New York: McGraw-Hill. 1962.

Zemlan. F. P.. Ward. I. L.. Crowley, W. R.. \& Margules. D. L. Activation of lordotic responding in female rats by suppression of serotonergic activity. Science. 1973, 179. 1010-1011.

(Received for publication June 11, 1973.)

\title{
Effects of prolonged training, differential housing, and response prevention on persisting avoidance in rats*
}

\section{FREDERIC J. SAUTTER and LARRY D. REID Bradley Liniversitn, Peoria. Ill. 61606}

Eight groups of five rats were trained to jump to a retractable shelf to avoid footshock. Before footshock was terminated and tests conducted for extinction of responding, one-half were trained for about 35 trials and one-half for about 310 trials. For 50 days prior to training, one-half of the rats lived individually in small

* This study was supported by Bradley's Board for Research which administers NSF Grant GU 3320. This study was part of a research program codirected by $H$. $R$. Miller who is now at Southern Illinois University. cages and one-half lived in large cages, 12 rats a cage. These two pretesting factors, plus a factor of presence or absence of response prevention given just before testing for extinction of avoidance, combined to vield a 2 by 2 by 2 experimental design. Rats took reliably longer to extinguish avoidance if they were trained more and if they were from group housing. The demonstration that pretraining housing is a reliable source of variance suggests that this factor should be controlled in studies of deconditioning of avoidance.

Baum (1965.1970) has described a procedure for efficiently training rats to avoid and has tested a number of ways to determine the most efficient ways to reduce perseveration of responding after footshock is 
terminated. Studies using the apparatus and general procedure of Baum (1965) typically vield large within-group variances. Among the reasons for inspecting these wide individual differences among rats are the interest in the differences themselves and the potential economy of reduced size of experimental groups that could accrue if these differences were controllable.

Lovely, Pagano, \& Paolino (1972) reported that shuttlebox avoidance performance in both acquisition and extinction was significantly affected by the amount of time rats had remained in individual housing prior to avoidance training. Rats taken from group housing performed with a median of one avoidance response during extinction with an interquartile range of 0 to 2.0. Rats housed in individual cages, however, responded in extinction with a median of 64 responses and with an interquartile range of 16 to 85 . Furthermore, the amount of individual housing was correlated with stress indices such as plasma corticosterone levels. To test for the effects of pretraining housing on performance in the shelfbox of Baum, rats were tested after either 0 or about 50 days of individual housing. Rats were also tested after brief or extended training and with and without response prevention (flooding) as a "treatment" for persisting avoidance.

\section{METHOD \\ Subjects}

Forty-eight male albino rats, purchased from Sprague-Dawley, Madison, Wisconsin, served as Ss. Upon arrival at the laboratory. they weighed about $150 \mathrm{~g}$ and were about 100 days of age. At this time, one-half of the rats were each housed in standard individual wire mesh cages, $24 \times 18 \times 18 \mathrm{~cm}$. The other rats were housed in one of two $60 \times 45 \times 68 \mathrm{~cm}$ cages, 12 rats to a cage. Rats remained in the cages for 50 to 55 days at which time avoidance training began. All rats had food and water available continuously.

\section{Apparatus}

The avoidance apparatus was nearly the same as the one described by Baum (1965). Briefly. it was a Plexiglas box $(30 \mathrm{x}$ $30 \times 39 \mathrm{~cm}$ ) with an electrifiable grid floor and a retractable shelf $(37 \times 14 \mathrm{~cm})$ which was $14 \mathrm{~cm}$ above the grid floor and protruded $7 \mathrm{~cm}$ into the box. The shock, always $1.3 \mathrm{~mA}$, was generated by a Grason-Stradler shock source and scrambler. Photocells sensed the presence of the rat on the shelf.

\section{Procedure}

After about 50 days of housing in their respective cages, six rats began testing each day; consequently, rats were housed from 50 to 55 days in their respective conditions. Without habituation to the apparatus, each rat began training by being placed directly on the grid. After $10 \mathrm{sec}$. the grid electrified and the rat received shock until it climbed to the shelf. After $30 \mathrm{sec}$ on the shelf, the shelf retracted. dropping the rat to the grid and beginning a new trial. Ten seconds later shock came on again. Rats could avoid shock on each trial by climbing to the shelf within $10 \mathrm{sec}$ after being returned to the grid. In the event that a rat left the shelf before $30 \mathrm{sec}$ had elapsed, the shelf automatically retracted, returned. and a new trial was begun.

One-half of the rats received their training. either response prevention or no response prevention, and testing for responding during extinction, all on the same day. These rats received 25 training trials, an unavoidable shock of $0.5 \mathrm{sec}$, and continued to receive training until the! made 10 consecutive aroidance. Th: other half of the rats received 100 trials a day for 3 consecutivi days. On the fourth day. prior to an opportunity to avoid. they received 0.5 sec of shock and then completed their training with 10 consecutive avoidances. The avoidable shock was given to insure that all rats had received recent shock just prior to the end of training.

With the end of training. footshock was terminated. One-half of the rats were then picked up. the shelf retracted. and the rats replaced on the grid for $5 \mathrm{~min}$. The other half were picked up and placed in a pail next to the chamber for $5 \mathrm{~min}$. After $5 \mathrm{~min}$. all rats were placed on the returned shelf. The shelf retracted at the end of $30 \mathrm{sec}$, beginning the trials to extinction. Extinction trials were like training trials. except that footshock did not come on, although the sounds of the shock scrambler did. Criterion for extinction was 5 consecutive minutes on the grid floor without a response.

The following measures were taken at training: (a) weights of Ss just prior to training, (b) amount of shock taken on first training trial. (c) total duration of shock, and (d) number of avoidances. These measures were taken during extinction: (a) latency of the first response under extinction conditions, (b) "avoidance" responses to criterion, i.e., climbs to the shelf prior to $10 \mathrm{sec}$ on the grid. (c) time the shock generator was on. even though the leads to the grid were disconnected, and (d) trials to extinction criterion. In addition to these formal measures, we observed the general condition and behavior of the rats.

\section{RESULTS}

Several researchers (Hatch et al, 1965; Lovely et al, 1972) have reported that their individually housed rats appeared to be more nervous, aggressive, and difficult to handle. We too observed these differences. In addition, the individually housed rats appeared heavier, i.e., they looked fatter. When weighed, however, the mean $(\mathrm{M})$ weight of the individually housed rats was $359.0 \mathrm{~g}$ compared to $358.5 \mathrm{~g}$ of the group housed Ss, an insignificant difference.

Analysis of variance (ANOVA) of amount of shock taken on the first training trial, with the Ss grouped according to the 2 by 2 by 2 design, indicated that Ss of group housing took less shock than Ss of individual housing $(\mathrm{M}$ shock of group housing $=11 \mathrm{sec}, \mathrm{M}$ of individual housing $=37 \mathrm{sec}, \mathrm{F}=34.1, \mathrm{df}=1 / 40$, $p<.001)$. All other Fs generated by this analysis failed to meet the standard $(\mathrm{p}<.05)$ for concluding there was a reliable effect with most Fs nearly one or less.

An ANOVA of the total seconds of shock taken throughout training was computed with the data grouped according to the 2 by 2 by 2 design even though one-half the Ss had about 310 training trials and the other about 35 training trials. The $\mathrm{M}$ of all Ss with 310 trials was $172.0 \mathrm{sec}$ of shock compared to the $\mathrm{M}$ of lesser training of $44.6 \mathrm{sec}$. With 310 training trials, rats of group housing took a $\mathrm{M}$ of $56.7 \mathrm{sec}$ of shock compared to $287.4 \mathrm{sec}$ for the individually housed rats. Rats of group housing not only took less shock on first trial but continued to take less shock throughout training. The ANOVA allows the conclusion that these means reflect reliable trends: $\mathrm{F}$ for the housing factor $=9.1, \mathrm{df}=1 / 40$, $\mathrm{p}<.01 ; \mathrm{F}$ for training factor $=8.5, \mathrm{df}=1 / 40, \mathrm{p}<.05$ : 
with all other $F$ s not being great enough to meet the standard.

There was no indication in the data that Ss of the lesser trained groups differed reliably from one another in number of escapes to training criterion. The criterion of 10 consecutive avoidances. after 25 training trials and brief footshock. was met in a $\mathbf{M}$ of 16 trials with limits to the range of 10 and 66 . with the next highest score of 25. Among Ss taking 310 training trials, a Student's t and means summarize the difference between group and individually housed $\mathrm{Ss}$ in number of escapes: $M$ for individually housed $=40$ escapes: $M$ for group housed $=$ 9 escapes $t=4.5 . \mathrm{df}=23 . \mathrm{p}<.005$. i.e.. on the average $13 \%$ of the trials of the individually housed Ss resulted in shock. whereas only $3 \%$ of the trials resulted in shock for group housed Ss. The $M$ trials to 10 consecutive avoidances just prior to treatment for the longer trained rats was 10.04 with limits to the range of 10 and 11 .

All posttraining response measures were shown to be similar by Kendall's coefficient of concordance $(\mathrm{W}=.70)$. Because of the degree of concordance between posttraining response measures and because analyses of each posttreatment measure lead to similar conclusions. only the trials to criterion are reported and discussed here.

Table 1 presents the $M$. median, and range of trials of extinction for each experimental group. The $\mathrm{M}$ trials to extinction for the rats which received 310 acquisition trials was 398.4 responses. while the lesser trained rats responded on an average of only 35.8 times. An ANOVA. with data grouped in the 2 by 2 by 2 design. showed the difference to be reliable $(\mathrm{F}=24.8 \mathrm{df}=$ $1 / 40 . p<.001)$. Group housed rats emitted an average of 319.6 responses while the $\mathrm{M}$ of the individually housed Ss was $114.5(\mathrm{~F}=7.9 . \mathrm{df}=1 / 40 . \mathrm{p}<.01)$. The ANOVA also indicated that there was a reliable Training by Housing interaction ( $F=4.9 . \mathrm{df}=1 / 40, \mathrm{p}<.05)$. All other Fs generated by the ANOVA were not large enough to conclude there were reliable differences. Five minutes of response prevention was ineffective with this amount of trianing. a finding confirming that of Gordon \& Baum (1971).

The interquartile range of trials to extinction of individually housed Ss ranged from 141 to 373 responses while the interquartile range for the group housed animals ranged from 6 to 213 responses. The correlation between trials to extinction and amount of shock taken during training was low (rho = .11). By following the procedure described by Hays (1964. p. 325) for determining the proportion of variance accounted for by a particular factor of an experiment. it was determined that $29 \%$ of the variance was attributable to the training factor. $9 \%$ to housing. and $5 \%$ to their interaction.

\section{DISCUSSION}

There is a reliable effect of preexperimental living conditions in this type of study which interacts with amount of training. Lovely et al (1972) also demonstrated a prexperimental housing effect but their individually housed rats. unlike these
Table 1

Trials to Extinction Criterion

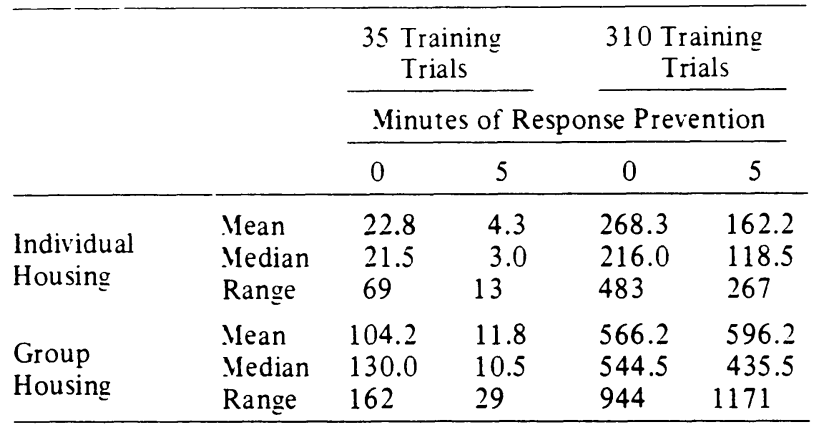

individually housed rats. responded more under extinction conditions. The apparatus and paradigm of Lovely et al were the traditional shuttlebox and one-way avoidance; in this study the apparatus and paradigm were a shelf-box and procedure described by Baum (1965). The conclusion is that preexperimental housing can be a reliable source of variance among rats in avoidance tasks but that there is a strong interaction between the housing effect and the type of avoidance task. It follows that if an $\mathrm{E}$ controls for this source of variance. he will reduce a potential source of both biased and "random" error.

We observed. as did Lovely et al, that individually housed rats seemed especially hyperactive and difficult to handle at the outset of training. a finding similar to Sturgeon \& Reid's (1971) who compared differences between "enriched" and "isolated" reared rats with regard to problem solving aptitude and emotionality. Rats of group housing had opportunities to practice climbing in their large cages and did extensive climbing up and down the cage sides; therefore. the rats of group housing were in potentially better physical condition for maintaining climbing. Heightened emotionality. enhanced by greater shock. would probably potentiate individually housed rats' shuttlebox performance but would not be potent enough to overcome the increased and more tiring work of shelf climbing demanded of the "out-of-shape" rats in the Baum apparatus.

With species. strain. age. sex, immediate preliving housing arrangement and gross features of training fixed or controlled. there still remain large individual differences in responding during extinction after avoidance training. notice the ranges presented in Table 1. Even though this study confirmed that preexperimental housing is a reliable source of variance and specified that it is a reliable source of variance in the Baum procedure there remain other potent sources of variance yet to be specified.

\section{REFERENCES}

Baum, M. An automated apparatus for avoidance training of rats. Psvchological Reports, 1965, 16, 1205-1211.

Baum, M. Extinction of avoidance responding through response prevention (flooding) in rats. Psychological Bulletin. 197.0. 74, 276-284.

Gordon. A.. \& Baum, M. Increased efficacy of flooding (response prevention). Journal of Comparative \& Physiological Psychology, 1971.75. 68-72.

Hatch. A.. Wiberg. G.. Zawidzka, Z.. Cann. M.. Airth, J. M.. \& Grice. $\vec{H}$. Isolation syndrome in the rat. Toxicology \& Applied Pharmacology. 1965, 7, 737-745.

Hays. W. L. Statistics for psychologists. New York: Holt, Rinehart \& Winston. 1964.

Lovely, R.. Pagano, R.. \& Paolino, R. Shuttle-box avidance performance and basal corticosterone levels as a function of duration of individual housing in rats. Journal of Comparative \& Physiological Psychology, 1972, 81, 331-336.

Sturgeon. R. D.. \& Reid. L. D. Rearing variations and Hebb-Williams maze performance. Psychological Reports. 1971.29.571-580.

(Received for pablication June 21.1973.1 